\title{
Social Context Effects in the Stroop Task: When Knowledge of One's Relative Standing Makes a Difference
}

Florence Dumas, Pascal Huguet and Edwige Ayme

\section{(2) OpenEdition \\ Journals}

Electronic version

URL: http://journals.openedition.org/cpl/456

DOI: $10.4000 / \mathrm{cpl} .456$

ISSN: $1379-6100$

Publisher

Centre PsyCLÉ

\section{Electronic reference}

Florence Dumas, Pascal Huguet and Edwige Ayme, « Social Context Effects in the Stroop Task: When Knowledge of One's Relative Standing Makes a Difference », Current psychology letters [Online], 16, Vol 2, 2005 | 2005, Online since 24 May 2005, connection on 07 September 2020. URL : http:// journals.openedition.org/cpl/456 ; DOI : https://doi.org/10.4000/cpl.456

This text was automatically generated on 7 September 2020

(C) All rights reserved 


\title{
Social Context Effects in the Stroop Task: When Knowledge of One's Relative Standing Makes a Difference
}

\author{
Florence Dumas, Pascal Huguet and Edwige Ayme
}

\begin{abstract}
Received December 20, 2004
Revised May 2, 2005

Accepted May 3, 2005

On line May 24, 2005

5 " To simplify the study of the mind, many scientists initially ignored the social aspects of human behavior with the notion that social processes could be considered later if the need arose; would be more explicable once the basics of the brain and mind were determined; or had minimal implications for basic development, structure, or processes of the human brain or mind » (Cacioppo, Berntson, Lorig, Norris, Rickett, and Nusbaum, 2003, p. 659). According to Cacioppo et al. (2003), however, evidence that humans are fundamentally social animals who can exist only in a web of relationships (Cacioppo, Bernston, Sheridan, \& McClintock 2000) and that even basic information processes can be modulated by the presence or actions of conspecifics (Cacioppo, 2002 ; Cacioppo et al. (2002) belies these early arguments. In line with this, Huguet, Galvaing, Monteil, and Dumas (1999) demonstrated that forced-comparison of one's performance with that of a superior coactor (physically present) prevents, at least temporarily, the spread of activation to the lexical-semantic level (what has been thought to be invariant automatic processing in Stroops' paradigm), as shown by a significant reduction of the well-known Stroop effect (see also Huguet, Dumas, \& Monteil, 2004). The current paper expands on this prior research. We report two new studies where the comparison others were simply mentally represented rather than physically present. The results offer evidence (first to date) that information about one's relative standing on the Stroop task is sufficient for a reduction of the Stroop effect to occur.
\end{abstract}


Stroop Effect and Social Context

6 The Stroop effect (Stroop, 1935) is one of the best-known effects in cognitive psychology. Research participants typically take much longer to name the ink color of a color word depicting a color incongruent with the ink color (e.g., the word RED printed in green) than to name the color of a patch of color, of a string of Xs or symbols, or of noncolor words. In his extensive review, MacLeod (1991) counted more than 700 articles dealing with this effect, either examining it directly or using it as a tool to study other cognitive processes, making the Stroop effect one of the most wellreplicated phenomena in experimental psychology. A core assumption of virtually all the theoretical accounts of this effect is that skilled readers process the incongruent word without conscious intent. The reading of the word is said to be automatic in the sense that readers cannot refrain from accessing the meaning of the word despite explicit instructions not to do so.

7 There is a large body of evidence, however, suggesting that few processes, if any, are entirely independent of attentional control (e.g., Logan, 1980). Besner, Stolz, and Boutilier (1997), for example, used a modification of the Stroop task in which only a single letter of the incongruent words was coloured. Stroop interference was either reduced or eliminated in this condition, suggesting that spatial attention was focused, thus preventing lexical-semantic activation (at least temporarily).

Preliminary evidence that the lexical-semantic level can be disabled and/or overridden by socio-contextual factors or factors not restricted to the local context of the task can be found in MacKinnon, Geiselman, and Woodward (1985). These authors used the standard vocal version of the Stroop task and tested the influence of interpersonal competition on the Stroop effect. Participants were tested either individually or in pairs. In the latter condition (competition), they were told that the fastest one on the task would receive one extra credit. While one participated in the Stroop session, the other waited outside until it was his/her turn. Competing for a reward increased selfreports of task-specific effort and the Stroop effect was $25 \%$ smaller in this condition, compared with the individual or no-competition condition. MacKinnon et al. concluded that subjects can reduce Stroop interference when their effort is focused in that direction.

9 Several arguments, however, make this motivational explanation not very plausible. First of all, it is well-known that a skilled reader's intent to not read the colour words is not enough to prevent lexical-semantic activation in the Stroop task (e.g., Reisberg, 1997). Second, recent results (Huguet et al., 1999, 2004) suggest that the presence of a desired reward (and related positive effect on self-reports of effort) did not play a key role in MacKinnon et al.'s findings. In Huguet et al.'s (1999) Study 2, participants performed a manual version of the Stroop task in the (supposedly incidental) presence versus absence of a confederate-coactor (i.e., a same-sex peer working simultaneously but independently on an identical task). Coaction facilitated Stroop performance, at least in participants faced with a coactor performing better than themselves on the Stroop task, suggesting that the presence of a self-threatening comparison other is a sufficient condition for MacKinnon et al.'s findings to occur. In MacKinnon et al.'s studies, all participants worked alone on the Stroop task. In the condition where a competitor was waiting outside the experimental room, however, they could ruminate about forthcoming interactions with the competitor during which a comparison of performance would take place. This could divert attention, at least temporarily, from 
the semantic level (i.e., could preclude the spread of activation to this level), resulting in a smaller Stroop effect. Huguet et al. (2004) tested the effects of competition more directly in a study where the physical presence (no longer incidental) versus absence of a competitor and of a desired reward were manipulated orthogonally during the Stroop session (both factors were confounded in MacKinnon et al.'s studies). As expected, whereas competition facilitated Stroop performance, it had no effect on the selfreports of effort. The prospect of a desirable reward increased the self-reports of effort but had no impact on the size of the Stroop effect. In a series of three studies, Chajut and Algom (2003) also concluded that the Stroop effect remains unchanged under heightened motivation but decreases under heightened stress (induced via non-social stressors such as intense noise). As they put it, improved selectivity of attention in the Stroop task «is not subject to strategic influences and is probably activated in an unconscious and default fashion on the appearance of stress» (p. 245). There is indeed ample evidence today that heightened level of arousal or stress impairs the attentional apparatus, with fewer resources available for more peripheral or less relevant information (Wells \& Matthews, 1994).

Finally, almost twenty-years ago, Baron (1986) reported several evidence that the presence of competitors is a sufficient condition for a relative narrowing of attention to occur. In settings where there is pressure to perform a task quickly and well, Baron reasoned, the self-threatening presence of others leads to attentional conflict, that is, a form of response conflict regarding what attentional response one should make, at least when attending to others is incompatible with task demands. This conflict typically increases stress and/or threatens the organism with cognitive overload (or both), two phenomena which, in turn, can lead (in combination or separately) to a restriction in attention focus (Cohen, 1978; Muller, Atzeni, \& Butera, 2004).

Whatever their explanation, the findings reported earlier (Huguet et al., 1999, 2004, MacKinnon et al., 1985), when examined together, suggest that a relative narrowing of attention and thus an alteration of the Stroop effect should still be found in a very minimal social condition. That is, 1) when the comparison others are not physically present but only mentally represented (as in MacKinnon et al., 1985), and simultaneously 2) when competitive pressures are not made salient, provided that the comparison others outperform the self (as in Huguet et al., 1999).

The present studies

12 The present studies tested this hypothesis in two different ways. In Study 1, participants were forced to compare their performance on practice Stroop trials with that of a physically present confederate-coactor (Time 1), and then worked alone on the Stroop task (Time 2). Participants who are slightly inferior to the coactor (upward comparison at Time 1), we predicted, should display a smaller stroop effect (Time 2) than those working alone at both Time 1 and Time 2, or those working in presence of a similar (lateral comparison) or inferior (downward comparison) coactor at Time 1. In Study 2, participants worked alone at both Time 1 and Time 2 in each condition. They simply received a feedback at Time 1 , which forced them to compare their performance on the practice trials with that of their reference (peer) group. A smaller Stroop effect was expected in participants who were faced with upward comparison than in those who did not receive comparison information, or those who received information indicating that they were either similar (lateral comparison) or slightly superior (downward comparison) to the group standard. 
Study 1MethodParticipants

Blaise Pascal University (Clermont-Ferrand), who volunteered to participate in partial fulfilment of a course requirement. Only females were retained because of the low number of males available at the time of the experiment. All participants were righthanded, reported normal or corrected-to-normal visual acuity, and were naive on the purpose of the experiments presented as part of a larger research project on colour perception.

Procedure and Materials

Preliminary phase. The participants arrived individually at the laboratory and were met by a female experimenter who described the Stroop task. Then they performed five practice sessions of 20 trials each including only colour-neutral words (e.g., CHAIR). They were asked to ignore the words and respond to the ink colours as quickly and as accurately as possible. On each trial, a word was presented at a fixation point in the center of a light grey computer screen (viewing distance $=60 \mathrm{~cm}$ ), in one of four colours (blue, green, red, or yellow). Each word was removed from the computer screen after $200 \mathrm{~ms}$ (with an interstimulus interval of $1 \mathrm{sec}$ ). Stimulus duration was long enough for the words to be read and/or the colour to be recognized. It was also short enough for each word to be off the screen before the computer key was pressed. The keys $\mathrm{K}$ (for BLUE ), $\mathrm{F}$ (for GREEN), S (for RED), and M (for YELLOW) were used as correct responses. They were covered by blue, green, red, and yellow adhesive labels, respectively. Participants positioned their index and middle fingers of their left and right hands on top of each of the keys. Half of them received the red and green labels on the left hand and the blue and yellow labels on the right hand, whereas for the other half the order was reversed. During the fifth training session, the four coloured labels were replaced with white labels so subjects knew that looking at the response keys was now useless.

Social Comparison manipulation. The participants performed the last training session either alone or in the incidental presence of a female (peer) confederate coactor, due to «technical problems in the adjacent room». The confederate immediately and publicly said to the experimenter that she had performed four training sessions before her computer crashed, so that participants were informed that she had exactly the same amount of practice as themselves on the task. Social comparison indeed does not necessarily occur (or does not necessarily affect performance) when the coactors differ on attributes related to the task at hand (Goethals \& Darley, 1977). Then, the confederate sat at another computer opposite the participants, within their peripheral vision. The experimenter gave the speed-accuracy instructions again, then the starting signal, and left the room. Throughout this last training session, participants were forced to compare their response speed with that of the confederate who made particularly loud keypresses that could not be easily ignored. The confederate responded either slightly more slowly, similarly, or slightly faster than the participants. This difference in performance speed was made possible by varying the confederate's interstimulus interval (which was identical to vs. longer or shorter of 500 ms than that of participants). Once the last training session ended, the participants were informed that they did not differ from the person present regarding response accuracy (same number of errors), and thus participants who were faced with a slower or faster coactor could readily attribute the difference in performance speed to a difference in ability.

Current psychology letters, 16, Vol. 2, 2005 | 2005 
16 The experimenter then publicly informed the confederate that the technical problem on her computer was now completely solved. She was invited to perform the Stroop task alone in the adjacent room. Participant, therefore, performed the Stroop task alone in each condition. The experimenter left the room in each condition on all sessions (training and Stroop).

17 After the Stroop task, participants in the coaction conditions were asked to rate how quickly they performed at training in relation to the coactor on a 7-point scale ranging from - 3 (much slower) to +3 (much faster), including zero (same speed). This manipulation check was also used as a measure of distraction related to social comparison (to be accurate some attention has to be allocated to the other person present). In order to see whether participants perceived that they did not differ from the coactor on response accuracy on the practice trials, they were also asked to rate how they were accurate on the task in relation to the coactor. This was made on a 7point scale ranging from "much less errors" (1) to "much more errors" (7), including zero (same number of errors). Finally, participants were debriefed.

18 Stroop task. The Stroop words were taken from MacKinnon et al. (1985). They included 4 colour words (BLUE, GREEN, RED, and YELLOW) that were part of the response set, 4 colour words that were not part of the response set (e.g., BLACK, GREY, ORANGE, and WHITE), and 12 colour-related words (e.g., SKY, CANARY). Each word was generated in one of the four target colours, excluding congruent colours. Control stimuli appeared as a row of three, four, five, or six coloured Xs. Each stimulus was generated twice by the computer, resulting in 80 test trials ( 40 incongruent words and 40 control signs). As in the training sessions, each stimulus was removed from the computer screen after $200 \mathrm{~ms}$. Stroop interference was measured by subtracting RTs for control signs (row of Xs) from RTs for incongruent words, which is the usual way of measuring it (see Kuhl \& Kazén, 1999; MacLeod, 1991). The use of congruent trials (e.g., the word RED printed in red) has also been recommended as the neutral baseline (Lindsay \& Jacoby, 1994). A drawback of this procedure, however, is that the inclusion of congruent trials provides an incentive for subjects to process irrelevant words (e.g., Besner, 2001). MacKinnon et al. (1985) used control signs (series of + signs), and this also influenced our decision to retain this baseline. Making use of a vocal Stroop task, as MacKinnon et al. did, was not appropriate in the present study where the participants and confederate's oral responses could interfere with each other at each trial during the last training session. However, there is evidence that the semantic level is also activated when subjects use the manual word response (Besner, 2001; McKenna \& Sharma, 1995).

Results

19 Manipulation checks. A One-Way ANOVA on perceived relative response speed at training showed a main effect of Social Comparison, $F(2,29)=43.53, p<.0001\left(\mathrm{Fg}_{\mathrm{g} g}^{2}=.75\right)$. Not only were the three corresponding means in the expected direction (Downward $=1.14$; Lateral $=0.18$; Upward $=-1.18$ ), but each differed significantly from the other two (Tuckey HSD, $p s<.05$ ). Also as expected, one sample t-tests indicated that each mean (Upward and Downward) but one (Lateral) differed significantly ( $p s<.0001)$ from the midpoint of the scale (0). No effects were found on perceived relative performance accuracy. Thus, the manipulations were clearly successful.

$R T$ data. Trials with RTs faster than $300 \mathrm{~ms}$ (1\% of the trials) or slower than $2500 \mathrm{~ms}$ (2 $\%$ of the trials) were excluded. The remaining RTs were then analyzed via a 2 (Stroop stimuli: Incongruent words vs. Control signs) x 4 (Social Comparison: None, Downward, 
Lateral, Upward) mixed analysis of variance (ANOVA), with Stroop stimuli as the within-subjects variable. This simple analysis (where RT from incorrect responses were not eliminated) was retained because it came close to that used by MacKinnon et al. (1985), and thus offered a more direct comparison with their data. In MacKinnon et al.'s studies, the Stroop stimuli were not isolated but presented all together on cards (different cards were used for the incongruent words and for the control signs). As a consequence, the processing times related to incorrect responses could not be removed. That being said, all the RT findings reported later in the present paper did also hold when only RT data from correct responses were retained, and then subjected to a recursive trimming procedure where the criterion cutoff for outlier removal was established independently for each subject, in each condition, by reference to the sample size in that condition (Van Selst \& Jolicoeur, 1994). In the first series of RT findings presented below, the incongruent colour words included each type of stimulus item (response-set colour words, non-response-set colour words, and colour-related words, see Table 1), as in MacKinnon et al. (1985).

Table 1. Stroop performance as a function of Social Comparison (standard errors in parentheses)

\begin{tabular}{|c|c|c|c|c|c|}
\hline & \multirow[b]{3}{*}{ n } & \multicolumn{4}{|c|}{ Social Comparison } \\
\hline & & None & Downward & Lateral & Upward \\
\hline & & 10 & 10 & 11 & 11 \\
\hline \multicolumn{6}{|l|}{ Incongruent Words } \\
\hline RT & & $782(38)$ & $822(25)$ & $760(34)$ & $672(27)$ \\
\hline Error Rate (\%) & & $2.25(0.79)$ & $2.25(0.69)$ & $2.27(0.86)$ & $2.50(0.48)$ \\
\hline Speed/Accuracy ( $(\mathrm{)})$ & & $-.55 a$ & -.03 & 37 & -24 \\
\hline \multicolumn{6}{|l|}{ Control Signs } \\
\hline RT & & $733(40)$ & 765 (28) & $715(28)$ & $662(23)$ \\
\hline Error Rate (\%) & & $1.00(0.41)$ & $1.00(0.55)$ & $1.36(0.70)$ & $3.18(0.59)$ \\
\hline Speed/Accuracy (r) & & -.00 & -.45 & -24 & 26 \\
\hline Mean RT & & $757(31)$ & $793(31)$ & $738(29)$ & $667(29)$ \\
\hline
\end{tabular}

Note. $a: p=.10$ (two-tailed)

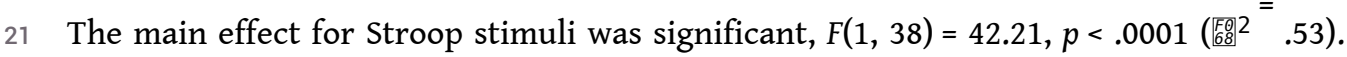
Faster RTs were found for the control signs $(M=717, S D=101)$ than for the incongruent words $(M=757, S D=113)$, indicating the emergence of a Stroop effect (40 ms). The main effect for Social Comparison was also significant, $F(3,38)=3.15, p<.04\left(\mathrm{EO}_{20}^{2}{ }^{2}\right.$.20). As showed by post-hoc contrasts (Tukey HSD), participants responded faster in the Upward than in the Downward Comparison condition $(p<.05)$. The expected Stroop stimuli $x$ Social Comparison interaction was significant as well, $F(3,38)=2.99, p<.05($ (F⿱ 6 2 .19). In order to better understand this interaction, it was broken down in three orthogonal contrasts with the Stroop difference score (Incongruent words - Control signs) as the dependent variable (see Figure 1). The first one contrasted the Upward Comparison condition $(10 \mathrm{~ms})$ with the average of the three other conditions $(50 \mathrm{~ms})$. The second contrasted the No-Comparison condition ( $49 \mathrm{~ms}$ ) with the average of the Downward and Lateral Comparison conditions (51 ms). Finally, the third contrasted the Downward (57 ms) and Lateral (45 ms) comparison conditions. As expected, only the 
first contrast was significant, $t(38)=-2.93, p<.007$. The Stroop effect was in fact not significant in the Upward Comparison condition, $t(10)=1.22, p=.25$. Using identical statistical power, it was clearly significant in each of the three other conditions ( $p s<$. 0001).

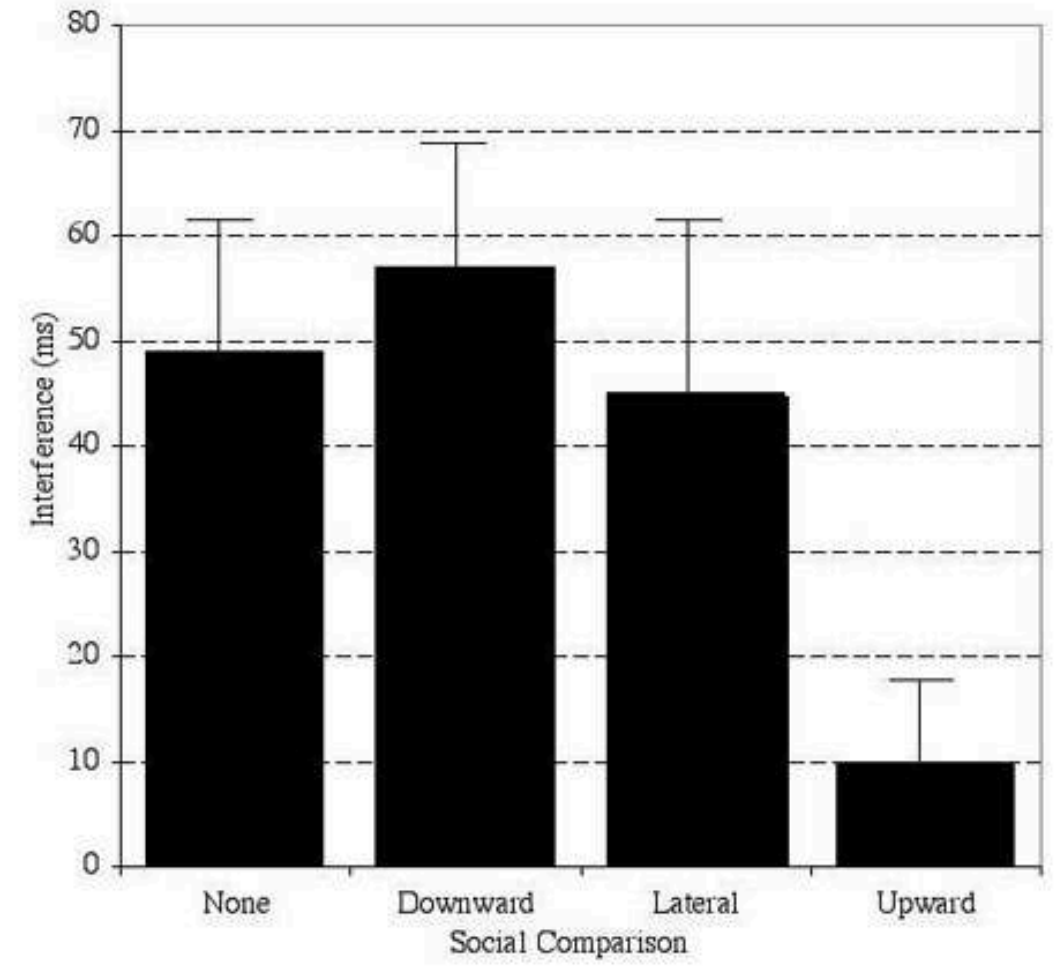

Figure 1. Stroop effect by social comparison

The Stroop effect is more commonly defined as the difference in RTs between responseset colour words and the baseline. Due to the group version of their Stroop task, MacKinnon et al. could not isolate this more conventional difference. Did the present findings hold when this difference was used as the dependent variable? It did: Among the three orthogonal contrasts used earlier for the global interference, the first one was still significant on the classic Stroop difference score $(56 \mathrm{~ms}$ for the Upward condition vs. $125 \mathrm{~ms}$ for the three other conditions averaged, $p<.05$ ).

Error Rate. Participants' error rate were analyzed using the same mixed analysis of variance as before. This analysis did not yield any significant effects. Clearly, the facilitating effect of upward comparison on response speed did not covary with any significant change in performance accuracy. As is typically the case with the Stroop task, participants' error rate was extremely low ( $2 \%$ on the Incongruent words and $2 \%$ on the Control signs, overall). Significant negative correlations between RTs and error rates might indicate a speed-accuracy trade-off if they are found only in the condition where the facilitation effects were found (Kulh \& Kazén, 1999). This was clearly not the case. Over the 8 correlations (see Table 1), 6 were negative and none of them were significant.

Discussion

It was predicted that upward comparison with a physically present coactor on practice Stroop trials (Time 1) would afterwards facilitate performance when working alone on the Stroop task (Time 2). This is exactly what we found. The Stroop effect was much 
smaller in the upward comparison condition than in the three other conditions (nocomparison, downward and lateral comparisons). Evidence that the participants in the coaction conditions really engaged in social comparison can be found in the mean of perceived speed difference ratings. All of these ratings were in the expected direction, indicating that some attention was allocated to the confederate (i.e., external distraction) at Time 1. Because each participant worked alone at Time 2 (Stroop task), the fact that upward comparison removed the Stroop effect cannot be due to external distractions. Internal distractions related to what happened to the self on the practice trials are more plausible here.

Their very nature remains unspecified, however. Upward comparison on the practice trials could trigger ruminations related to one's inferiority during the Stroop session, at the time during which the Stroop words were processed. But it could also activate some thoughts about the diagnosticity of the comparison episode itself. After all, the meaning of such an episode depends on whether the more successful comparison other reflects the norm or is simply an especially efficient person, that is, someone exceptional and not reflecting the norm (see Alicke, LoSchiavo, Zerbst, \& Zhang, 1997; Tesser, 1988 ). In addition, during the Stroop session, participants could anticipate an interaction (at the end of the experiment) with the person present at training (Time 1). The coactor's typicality and the anticipated interaction with this person, both could also divert attention, at least temporarily, from the semantic level, resulting in a smaller Stroop effect. Thus, one question that arises is whether this smaller Stroop effect can still be associated with upward comparison when distracting cognitions related to the diagnosticity of the comparison and/or forthcoming interactions with the comparison other are eliminated from the experimental setting.

of particular interest here, the typicality of the coactor is a very common and seldom addressed question in social comparison studies. All the more reason for us to address this question in Study 2, in which participants were forced to compare themselves with their peer group rather than with a single person. Because the average performance of one's peer group reflects a valuable norm, comparisons with this standard are indeed especially diagnostic of one's level of ability (at least more diagnostic than comparisons with a single person). Consistent with this, there is today ample evidence that people typically choose to compare their personal attributes (abilities as well as opinions) within their peer group (Zanna, Goethals, \& Hill, 1975; see also Huguet, Dumas, Monteil, \& Genestoux, 2001). If feelings about one's inferiority per se (i.e., regardless of other sources of distraction related to the diagnosticity of the comparison episode and/ or anticipated interaction) are sufficient for a reduction of the Stroop effect to occur, we reasoned, then this reduction should still be found when participants are simply forced to compare upward with their peer group (while working alone at both Time 1-practice trials and Time 2--Stroop session).

Study 2MethodParticipants

Thirty-two introductory psychology students (26 females and 6 males from 18 to 22 years old) at Blaise Pascal University (Clermont-Ferrand) participated in return for extra course. All participants were right-handed, reported normal or corrected-tonormal visual acuity, and were naive on the purpose of the experiment.

Procedure and Materials

This second study differed from the previous one only on two points. First of all, before the Stroop session, participants performed four (instead of five) series of practice 
Stroop trials (because of the low number of errors found at session 4 in the previous study). Second, and most important, at the end of the fourth training session, participants were instructed that their average reaction time and error rate will be compared to those of previous participants as themselves. Previous participants, it was said, were «male and female undergraduates from psychology (major) who came from your own university ». This comparison was presented as a means to better understand the meaning of participants' data. They were informed that their error rate was both less than 3\% (which was true) and similar to that of most previous participants. Then it was said that the previous participants responded between 735 and $765 \mathrm{~ms}$ in average, and then the current participants were informed about their own (bogus) mean RT: In the downward, lateral, and upward comparison conditions, this RT was 599, 750, and $901 \mathrm{~ms}$, respectively. For clarity, the experimenter said that, compared with the previous participants, they had performed «slightly faster» (downward condition), «similarly" (lateral condition), and «slightly slower» (upward condition). The participants were then faced with the Stroop task alone in each condition.

Results

Stroop Performance. RTs were analyzed as before. The data are reported in Table 2. The main effect for Stroop stimuli was significant, $F(1,28)=63.47, p<.0001\left(\mathrm{Fg}_{\mathrm{g}}^{2}=.69\right)$. Longer RTs were found for the Incongruent words $(M=967, S D=139)$ than for the Control signs $(M=902, S D=124)$, indicating the presence of a Stroop effect $(65 \mathrm{~ms})$. Although the mean RT was relatively low in the Upward condition (as previously), the main effect for

Social Comparison was not really significant, $\left.F(3,28)=1.98, p=.14\left(\mathrm{~F}_{[62}^{2} 2\right)=18\right)$. In contrast, the Stroop stimuli $\mathrm{x}$ Social Comparison interaction was still clearly significant, $F(3,28)=4.19, p<.02\left(\left(_{[60}^{\mathbb{E} 2} 2=.31\right)\right.$.

Table 2. Stroop performance as a function of Social Comparison Feedback (standard errors in parentheses)

\begin{tabular}{|c|c|c|c|c|c|}
\hline & & \multicolumn{4}{|c|}{ Social Comparison } \\
\hline & & None & Downward & Lateral & Upward \\
\hline & n & 8 & 8 & 8 & 8 \\
\hline \multicolumn{6}{|l|}{ Incongruent Words } \\
\hline RT & & $1028(33)$ & $993(43)$ & $994(54)$ & $853(47)$ \\
\hline Error Rate (\%) & & $1.56(0.94)$ & $3.13(0.91)$ & $0.31(0.31)$ & $3.13(0.78)$ \\
\hline Speed/Accuracy $(\tau)$ & & .06 & 26 & 22 & 33 \\
\hline \multicolumn{6}{|l|}{ Control Signs } \\
\hline RT & & $934(29)$ & $916(42)$ & $921(52)$ & $836(49)$ \\
\hline Error Rate (\%) & & $0.31(0.31)$ & $1.88(1.23)$ & $1.25(0.47)$ & $0.94(0.46)$ \\
\hline Speed/Accuracy $(r)$ & & 10 & -44 & -.30 & -.17 \\
\hline Mean RT & & $981(44)$ & $954(44)$ & $958(44)$ & $844(44)$ \\
\hline
\end{tabular}

This interaction was broken down in the same three orthogonal contrasts as before, with the Stroop difference score as the dependent variable (Figure 2). The first one contrasted the Upward Comparison condition $(17 \mathrm{~ms})$ with the average of the three other conditions ( $81 \mathrm{~ms})$. The second contrasted the No-Comparison condition (94 ms) with the average of the Downward and Lateral Comparison conditions (75 ms). Finally, the third contrasted the Downward (77 ms) and Lateral (73 ms) comparison conditions. Once more, only the first contrast was significant, $t(1,28)=3.40, p<.003^{1}$. In the Upward 
comparison condition, the Stroop difference score was not statistically significant, $t(7)=1.34, p=.22$. Using identical statistical power, it was clearly significant in each of the three other conditions ( $p s<.0001)$.

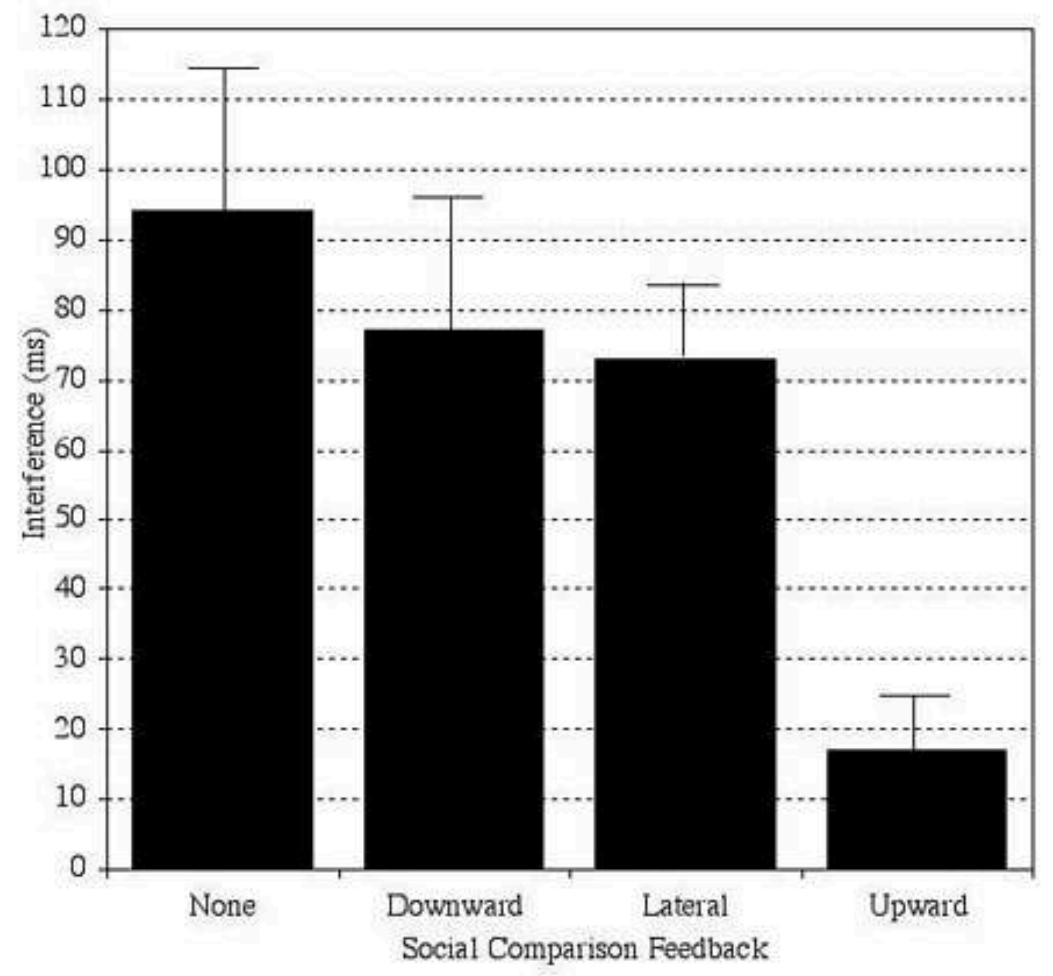

Figure 2. Stroop effect by social comparison

As in Study 1, among the three orthogonal contrasts used earlier for the global interference, only the first one was significant on the classic Stroop effect (62 ms for the Upward condition vs. $234 \mathrm{~ms}$ for the three other conditions averaged, $p<.01$ ). One may wonder why the global as well as classic Stroop effect were here slightly higher than in Study 1. Participants performed only four practice sessions (not five as before), and this may help explain this difference between the two studies.

Error Rate. Once more, this analysis did not yield any significant effects. Participants' error rate was extremely low ( $2 \%$ on the Incongruent words and $1 \%$ on the Control signs, overall). Correlational analyses did not support a speed-accuracy trade-off interpretation of the data (Table 2).

General Discussion

The present findings deserve attention in a number of important ways. First of all, they clarify the conditions under which a social comparison standard promotes a relative narrowing of attention, and thus an alteration of the Stroop effect. MacKinnon et al. (1985) reported evidence that this effect is reduced when competing with others for a desired reward. Huguet et al. $(1999,2004)$ demonstrated that this reduction did not result from the perspective of being rewarded and was due to the self-threatening presence of comparison others. The present findings go a step further. They show that the Stroop effect is reduced whenever the subject is threatened by social comparison, even in the lack of competitive instructions and comparison others during the Stroop session (i.e., at the time during which the Stroop words are processed). Clearly, the 
threat of being inferior to significant others seems to be sufficient for an alteration of the Stroop effect to occur.

Consistent with this, there is evidence that the state of failure can promote a relative narrowing of attention (Wells \& Matthews, 1994). This had not been shown in the Stroop task, however. Our findings do not mean that failure or at least the threat of being inferior to others does necessarily cause attention to focus. When failure at a given task is socially shared, or can be attributed to external factors (e.g., the context of task performance), it is simply not meaningful and can be ignored. Here, participants who compared upward could not easily ignore their inferiority. Once more, in the two studies, they were led to believe that the comparison others were similar to them on several attributes potentially related to the Stroop task (same age, same affiliation, same number of practice trials). They were also made comparable to the social standard regarding response accuracy. As a consequence, those faced with upward comparison (and with downward comparison as well) could readily attribute the difference in performance speed to a difference in ability. Ability inferences is probably a pre-condition for findings such as those reported here to occur. Exactly why should upward comparison alter Stroop interference in the lack of these inferences? One may think that seeing, or at least thinking about others doing better than themselves conducted participants to set higher personal standards (Seta, 1982), or to identify themselves with the more successful others (Blanton, Buunk, Gibbons, \& Kuyper, 1999; Collins, 1996; Huguet et al., 2001; Rijsman, 1983), which, in turn, motivated task-specific efforts. Again, however, there is ample evidence that the Stroop effect remains unchanged under heightened motivation but decreases under heightened stress (Chajut \& Algom, 2003; Huguet et al., 2004). Thus, there are good reasons to believe that feelings about one's inferiority did play a key role in the present findings.

Second, as suggested earlier in this paper, that a self-related threat (here due to upward comparison information or feedback) reduces otherwise eliminates the Stroop effect is consistent with a number of theories relating stress/emotional arousal and attention. According to Baron's (1986) distraction-conflict theory, for example, evaluative threats, at least when attending to them conflicts with task demands, are expected to increase emotional arousal and/or cognitive overload (or both). Two phenomena which, in turn, can lead (in combination or separately) to a restriction in attention focus, so that individuals attend more to cues that are most central to the task (or alternatively most central spatially in the display) at the expense of more peripheral cues, as also suggested by a large body of data in the attention literature (Broadbent, 1971 ; Cohen, 1978 ; Eysenck, 1982 ; Derryberry \& Reed, 2001; Kahneman, 1973; Newman, Wallace, Strauman, Skolaski, Oreland, Mattek, Elder, \& McNeely, 1993 ; Wells \& Matthews, 1994). From Baron's theory, therefore, participants who were faced with upward comparison displayed a smaller Stroop effect due to a restriction in attention focus that led them to screen out the incorrect semantic cues and focus more exclusively on the letter color cues.

Chajut and Algom (2003) also concluded that heightened stress/emotional arousal improves the selectivity of attention, so that word recognition processes operate less efficiently, as indicated by a significant reduction of the Stroop effect. Using two classes of selectivity measures (Stroop and Garner effects), they demonstrated that the impact of Stress is not perceptual, as the salience of the relevant and irrelevant dimensions remained unchanged under high and low stress. It is not spatial either, because 
heightened stress reduced the Stroop effect even when the color and the word overlaped in space (as in the present studies). As noted by Chajut and Algom (2003), this latter point is important because restricted focusing has often been interpreted in the spatial sense as a more narrowly concentrated beam (Chajut, 1996; Tsal\& \& Shalev, 1996, Urbach \& Spitzer, 1995 ; cf. Posner, Snyder, \& Davidson, 1980), as enhanced processing of central stimuli (Baddeley, 1992), as the relative neglect of low-probability stimuli (Hockey \& Hamilton, 1983), or as the actual shrinkage of the effective visual field (Williams, Tonymon, \& Andersen, 1990, 1991). We agree that these notions do not apply when the relevant (color) and irrelevant (word) dimensions inhere in the same spatial location. Since the stress effect is not motivational (see Chajut \& Algom's Study 3, see also Huguet et al., 2004), we also agree with Chajut and Algom (2003) that stress seems to improve the ability of people «to decompose the stimulus in its constituent dimensions» (p. 245), a mechanism which, again, is probably activated in an unconscious and default fashion on the appearance of stress.

Likewise, our findings are compatible with Easterbrook's (1959) classic «cueutilization» hypothesis, which predicts that increased stress/emotional arousal reduces the range of cue-utilization. From this view, irrelevant cues are eliminated before relevant ones as capacity diminishes. Low level of arousal would thus result from the simultaneous use of relevant and irrelevant information, and high level of arousal from incomplete utilization of relevant information (see also Humphreys \& Revelle, 1984). On this basis, it can be reasonably assumed that upward comparison information or feedback induced a moderate level of stress/emotional arousal which, in turn, decreased the ability to process semantically (at least temporarily) and hence reduced the size of the Stroop effect. The smaller Stroop effect was associated here (especially in Study 1) with a global acceleration of responses to all stimuli (incongruent words and control signs), which can also be taken as evidence that upward comparison increased stress/emotional arousal (Cohen, 1978).

This global acceleration, however, runs counter to our earlier rumination hypothesis: Would internal distractions or ruminations related to one's inferiority not increase rather than decrease the mean $\mathrm{RT}^{2}$ ? It seems therefore that upward comparison increased stress/arousal but did not trigger distracting or task-irrelevant thoughts, at least at the time during which the Stroop words were processed. Maybe that cognitions related to one's inferiority (i.e., self-focused attention) vanished quickly after the comparison information or feedback but led toward heightened level of stress/arousal during the Stroop session. There is indeed ample reasons to believe that heightened stress/arousal alone is a sufficient condition for the present findings to occur (e.g., Baron, 1986). Furthermore, there is some evidence today that whereas distractor processing is reduced in conditions of high perceptual load (manipulated by relevant display set size or by different processing requirements for identical displays), it is increased in conditions of high working memory load (Lavie, 2005 ; Lavie, Hirst, de Fockert, \& Viding, 2004). From this emerging literature ${ }^{3}$, ruminations about one's inferiority at the time during which the Stroop words were processed would have undermine the participants' capacity to actively maintain current processing priorities (i.e., identifying the color rather than the word as fast as possible while minimizing errors) which, in turn, would have increase both the mean RT and Stroop interference itself. This is not what happened, quite the contrary. 

Danziger, 2000 ), the reduction or even elimination of a Stroop effect does not speak to the ultimate fate of the words. Does this reduction (or elimination) necessarily mean that word processing at the semantic level is altered? It does not. MacKinnon et al. (1985) as well as Huguet et al. (1999) found some signs of this alteration, as the smaller Stroop effect was associated with a reduction in recognition memory for the Stroop words (suggesting that attention affected Stroop interference at an early stage where the degree of semantic processing could be altered). In Huguet et al.'s (2004) study, however, the smaller Stroop effect occurred while recognition memory was unchanged (while using exactly the same material as before). This dissociation (i.e., decreased Stroop effect with word processing unchanged) is consistent with Mari-Beffa et al.'s (2000) claim that the reduction of the Stroop effect is not sufficient evidence for concluding that word-level processing is altered (see also Bibi, Tzelgov, \& Henik, 2000). Mari-Beffa et al. (2000) and Besner (2001), all used the negative priming effect for their demonstration. Negative priming in the Stroop paradigm refers to the observation that ignoring one stimulus dimension in a display (i.e., prime display) interferes with responding to the other stimulus dimension in a subsequent display (i.e., target display), if they are related (e.g., ignoring the word BLUE in the prime display and identifying the colour blue in the target display). One way of finding out whether the reduction or elimination of a Stroop effect is associated with an alteration of word processing is to see whether this reduction or elimination is associated with a negative priming effect. Mari-Beffa et al. (2000) found this effect in the absence of Stroop interference. Besner (2001) found a negative priming effect despite the elimination of Stroop interference. Both findings lead one to conclude that the Stroop effect is not an exhaustive measure of word processing. A reduced Stroop effect with unchanged longterm memory for the Stroop words (Huguet et al., 2004) leads to exactly the same conclusion. Negative priming or recognition memory were not measured here and thus deciding whether upward comparison did or did not alter word processing is difficult, to say the least. What can be said is that this comparison made a huge difference in the size of the Stroop effect.

Finally, this effect has been shown to be extremely robust when the local context of the Stroop task is unchanged (i.e., all letters coloured, words and colours simultaneously presented in the same spatial location, same number of incongruent words and baseline items). In this standard condition, the reduction and even more so the elimination of Stroop interference seems highly unlikely. This is another reason why the present findings are especially interesting. They show that self-related information arising from the social world can influence cognitive phenomena which are yet typically examined outside social psychology. 


\section{BIBLIOGRAPHY}

Alicke, M. D., LoSchiavo, F. M., Zerbst, J., \& Zhang, S. (1997). The person who outperforms me is a genius : Maintaining perceived competence in upward social comparison. Journal of Personality and Social Psychology, 73,781-789.

Baron, R. S. (1986). Distraction-conflict theory: Progress and problems. In L. Berkowitz (Ed.), Advances in Experimental Social Psychology (pp. 1-40). New-York: Academic Press.

Besner, D. (2001). The myth of ballistic processing: Evidence from Stroop's paradigm. Psychonomic Bulletin and Review, 8, 324-330.

Besner, D., Stolz, J. A., \& Boutilier, C. (1997). The Stroop effect and the myth of automaticity. Psychonomic Bulletin \& Review, 4, 221-225.

Bibi, U., Tzelgov, J., \& Henik, A. (2000). Stroop effect in words that differ from colour words in one letter only. Psychonomic Bulletin and Review, 7, 678-683.

Blanton, H., Buunk, B. P., Gibbons, F. X., \& Kuyper, H. (1999). When better-than-others compare upward: Choice of comparison and comparative evaluation as independent predictors of academic performance. Journal of Personality and Social Psychology, 76, 420-430.

Broadbent, D. E. (1971). Decision and stress. New York : Academic Press.

Cacioppo, J. T. (2002). Social neuroscience in perspective : Understanding the pieces contributes to understanding the whole and vice versa. American Psychologist, 57, 819-831.

Cacioppo, J. T., Berntson, G. G., Adolphs, R., Carter, C. S., Davidson, R. J., \& McClintock, M. K. et al. (Eds.) (2002). Foundations in social neuroscience. Cambrige, MA : MIT Press.

Cacioppo, J. T., Berntson, G. G., Lorig, T. S., Norris, C. J., Rickett, E., \& Nusbaum, H. (2003). Just because you're imaging the brain doesn't mean you can stop using your head : A primer and set of first principles. Journal of Personality and Social Psychology, 85, 650-661.

Cacioppo, J. T., Bernston, G.G., Sheridan, J. F., \& Mcclintock, M.K. (2000). Multi-level integrative analyses of human behavior : Social neuroscience and the complementing nature of social and biological approaches. Psychological Bulletin, 126, 829-843.

Chajut, E. (1996). Narrowing of visual attention under stress conditions. Unpublished master's thesis, Tel-Aviv University, Tel-Aviv, Israel.

Chajut, E., \& Algom, D. (2003). Selective attention improves under stress: Implications for theories of social cognition. Journal of Personality and Social Psychology, 85, 231-248.

Cohen, S. (1978). Environmental load and the allocation of attention. In A. Baum, J. E. Singer, \& S. Valins (Eds.), Advances in Environmental Psychology. Hillsdale, NJ : Lawrence Erlbaum.

Collins, R. L. (1996). For better or worse : The impact of upward social comparison on self evaluations. Psychological Bulletin, 1, 51-69.

Derryberry, D. \& Reed, M. A. (2001). A multidisciplinary perspective on attentional control. In C. L. Folk, \& S. Bradley (Eds.), Advances in Psychology: Vol. 133. Attraction, distraction and action: Multiple perspectives on attentional capture. (pp. 325-347). New York : Elsevier Science.

Easterbrook, J. A. (1959). The effect of emotion on cue utilization and the organization of behavior. Psychological Review, 66, 183-201. 
Eysenck, M. W. (1982). Attention and arousal : Cognition and performance. New York : SpringerVerlag.

Goethals, G. R., \& Darley, J. (1977). Social comparison theory: An attributionnal approach. In J. Suls \& R. L. Miller (Eds.), Social comparison processes: Theoretical and empirical perspectives (pp. 259-278). Washington, DC: Halsted-Wiley.

Hockey, G. R. J., \& Hamilton, P. (1983). The cognitive patterning of stress states. In G. R. J. Hockey (Ed.), Stress and fatigue in human performance (pp. 331-362). Chichester, England : Wiley.

Huguet, P., Dumas, F., \& Monteil, J.-M. (2004). Competing for a Desired Reward in the Stroop Task : When Attentional Control is Unconscious but Effective versus Conscious but Ineffective. Canadian Journal of Experimental Psychology, 58, 153-167.

Huguet, P. Dumas, F., Monteil, J.-M., \& Genestoux, N. (2001). Social comparison choices in the classroom: Further evidence for students' upward comparison tendency and its beneficial impact on performance. European Journal of Social Psychology, 31, 557-578.

Huguet, P., Galvaing, M.P., Monteil, J.-M., \& Dumas, F. (1999). Social Presence Effects in the Stroop Task: Further Evidence for an Attentional View of Social Facilitation. Journal of Personality and Social Psychology, 77, 1011-1025.

Humphreys, M. S., \& Revelle, W. (1984). Personality, motivation and performance: A theory of the relationship between individual differences and information processing. Psychological Review, $91_{2}$ 153-184.

Kahneman, D. (1973). Attention and effort. Englewood Cliffs, NJ : Prentice Hall.

Kulh, J. \& Kazén, M. (1999). Volitional facilitation of difficult intentions: Joint activation of intention memory and positive affect removes Stroop interference. Journal ofExperimental Psychology: General, 128, 382-399.

Lavie, N. (2005). Distracted and confused ? : Selective attention under load. Trends in Cognitive Sciences, 9, 2, 75-82.

Lavie, N., Hirst, A., de Fockert, J. W., \& Viding, E. (2004). Load theory of selective attention and cognitive control. Journal of Experimental Psychology : General, 133, 3, 339-354.

Lindsay, D. S., \& Jacoby, L. L. (1994). Stroop process dissociations: The relationship between facilitation and interference. Journal of Experimental Psychology: Human Perception and Performance, 20, 219-234.

Logan, G. D. (1980). Attention and automaticity in Stroop and priming tasks: Theory and data. Cognitive Psychology, 12, 523-553.

McKenna, F. P., \& Sharma, D. (1995). Intrusive cognitions: An investigation of the emotional Stroop task. Journal of Experimental Psychology: Learning, Memory, and Cognition, 21, 1595-1607.

MacKinnon, D. P., Geiselman, R. E., \& Woodward, J. A. (1985). The effects of effort on Stroop interference. Acta Psychologica, 58, 225-235.

MacLeod, C. M. (1991). Half a century of research on the Stroop effect: An integrative review. Psychological Bulletin, 109, 163-203.

Mari-Beffa, P., Estevez, A. F., \& Danziger, S. (2000). Stroop interference and negative priming: Problems with inferences from null results. Psychonomic Bulletin and Review, 7, 499-503. 
Muller, D., Atzeni, T., \& Butera, F. (2004). Coaction and upward social comparison reduce the illusory conjunction effect: Support for distraction-conflict theory. Journal of Experimental Social Psychology, 40, 659-665.

Newman, J. P., Wallace, J. F., Strauman, T. J., Skolaski, R. L., Oreland, K. M., Mattek, P. W., Elder, A., \& McNeely, J. (1993). Effects of motivationally significant stimuli on the regulation of dominant responses. Journal of Personality and Social Psychology, 65, 165-175.

Posner, M. I., Snyder, R. R., \& Davidson, D. J. (1980). Attention and the detection of signals. Journal of Experimental Psychology : General, 109, 160-174.

Reisberg, D. (1997). Cognition: Exploring the science of the mind. New York: Norton.

Rijsman, J. (1983). The dynamics of social competition in personal and categorical comparisonsituations. In W. Doise \& S. Moscovici (Eds.), Current issues in European Social Psychology (Vol. 1, pp. 279-312). London: Wiley.

Seta, J. J. (1982). The impact of comparison processes on coactors' task performance. Journal of Personality and Social Psychology, 42, 2, 281-291.

Stroop, J. R. (1935). Studies of interference in serial-verbal reaction. Journal of Experimental Psychology, 18, 643-662.

Tesser, A. (1988). Toward a self-evaluation maintenance model of social behavior. In L. Berkowitz, Advances in experimental social psychology (pp. 181-227). San Diego, CA: Academic Press.

Tsal, Y., \& Shalev, L. (1996). Inattention magnifies perceived length : The attentional receptive field hypothesis. Journal of Experimental Psychology : Human Perception and Performance, 22, 233-243.

Urbach , D., \& Spitzer, H. (1995). Attentional effort modulated by task difficulty. Vision Research, $35,2169-2177$.

Van Selst, M., \& Jolicoeur, P. (1994). A solution to the effect of sample size on outlier elimination. The Quaterly Journal of Experimental Psychology, 47A, 631-650.

Wells, A., \& Matthews, G. (1994). Attention and emotion. Hove, East Sussex: LEA.

Williams, J. M., Tonymon, P., \& Andersen, M. B. (1990). Effects of life-event stress on anxiety and peripheral narrowing. Behavioral Medecine, 16, 174-181.

Williams, J. M., Tonymon, P., \& Andersen, M. B. (1991). The effects of stressors and coping resources on anxiety and peripheral narrowing. Journal of Applied Sport Psychology, 3, 126-141.

Zanna, M. P., Goethals, G. R., \& Hill, J. F. (1975). Evaluating a sex-related ability: Social comparison with similar others and standard setters. Journal of Experimental Social Psychology, 11, 86-93.

\section{NOTES}

1.This contrast was still significant while removing the male participants, $\underline{t}(1,21)=2.69$, $\underline{p}<02$. Both the main effect for Stroop stimuli, $\underline{F}(1,21)=39.60, \underline{p}<.0001(\underline{\underline{68}} 2=.65)$, and the Stroop stimuli $x$ Social Comparison interaction, $\underline{F}(3,21)=3.02, \underline{p}=.05\left(\underline{\underline{600}}^{2}=.30\right)$, were also significant with this smaller sample.

2.For information, this effect (decreased mean RT) did not always occur in past research. Whereas it was present in Huguet et al.'s (2004) study, where the person present (confederate) was explicitly presented as a competitor, it was not in Huguet et al.'s (1999) coaction study, in which the coactor's presence was supposedly incidental. 
3.This literature in fact suggests the existence of two selective attention mechanisms: a mechanism serving to reduce distractor perception in situations that exhaust perceptual capacity (a rather passive mechanism whereby irrelevant distractor interference is prevented simply because there is insufficient capacity for processing the distractors), and a cognitive control mechanism that reduces interference from perceived distractors as long as cognitive control functions are available to maintain current priorities (low or moderate cognitive load).

\section{ABSTRACTS}

This paper expands on prior research demonstrating the power of social comparison in Stroop's paradigm. In two experiments, it is shown that the Stroop effect is reduced whenever the subject is threatened by social comparison, even in the lack of competitive instructions and comparison others during the Stroop session. These new findings show that self-related information arising from the social world can influence cognitive phenomena which are yet typically examined outside social psychology.

Cet article s'inscrit dans le prolongement d'une série de recherches faisant apparaître la comparaison sociale comme un puissant régulateur de l'effet Stroop. Les résultats de deux études expérimentales montrent que cet effet est réduit dès lors que le sujet est confronté à une comparaison qui lui est défavorable, cela même en l'absence d'instructions compétitives et des personnes impliquées dans cette comparaison au moment de l'activité cible. Ces nouveaux résultats montrent que des informations en rapport à soi issues de l'environnement social peuvent influencer des phénomènes cognitifs encore typiquement étudiés en dehors de la psychologie sociale.

INDEX

Keywords: Attention, Automaticity, Social Context, Stroop Effect

\section{AUTHORS}

\section{FLORENCE DUMAS}

Laboratoire de Psychologie Cognitive, CNRS/Université de Provence, 3 Place Victor Hugo, Case D, 13331 Marseille, Cedex 03, France

Tel.: +33491518874 / Fax: +33488576895

flodumas.home@wanadoo.fr

\section{PASCAL HUGUET}

Laboratoire de Psychologie Cognitive, CNRS/Université de Provence, France huguet@srvpsy.univ-bpclermont.fr 


\section{EDWIGE AYME}

Jean-Marc Monteil 